
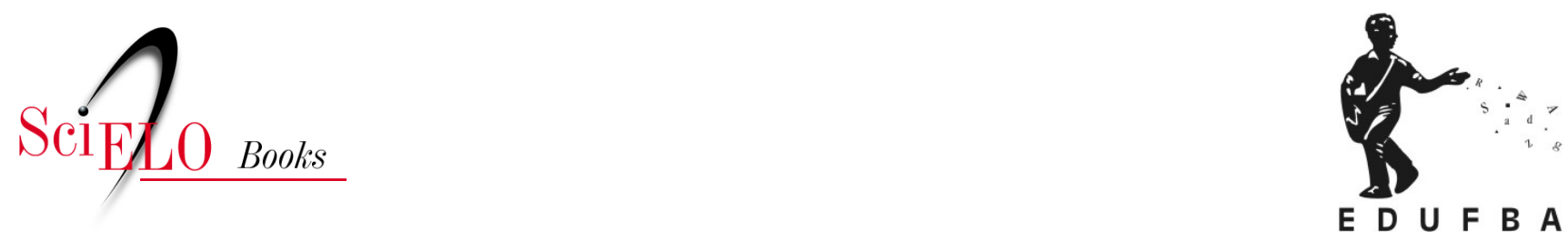

\title{
Política Brasil sorridente
}

\author{
Thais Regis Aranha Rossi
}

\section{SciELO Books / SciELO Livros / SciELO Libros}

ROSSI, T.R.A. Política Brasil sorridente. In: Produção social das políticas de saúde bucal no Brasil [online]. Salvador: EDUFBA, 2018, pp. 179-198. ISBN 978-85-232-2022-8.

https://doi.org/10.7476/9788523220228.0009.

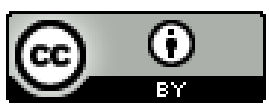

All the contents of this work, except where otherwise noted, is licensed under a Creative Commons Attribution 4.0 International license.

Todo o conteúdo deste trabalho, exceto quando houver ressalva, é publicado sob a licença Creative Commons Atribição 4.0. 


\section{POLÍTICA BRASIL SORRIDENTE}

Um novo documento intitulado "Política Nacional de Saúde Bucal no Brasil PNSB” publicado em 2004, formalizou as políticas de atenção à saúde bucal no Brasil a partir desta data - a política "Brasil Sorridente".

Alguns autores como Andrade (2008) e Narvai (2011), consideram que o início da formulação da PNSB, de 2004, partiu de movimentos desencadeados desde as décadas de 1970 e 1980). Narvai (2011), participante da comissão de assessoramento, recupera uma longa gênese deste processo iniciada na luta contra a ditadura militar e com ganho de expressão técnico-política nos ECEO, Enatespo, congressos de Odontologia e Saúde Coletiva, conferências de saúde e entidades como a FIO, a Aboprev, Reforma Sanitária Brasileira, o MBRO e da Saúde Bucal Coletiva.

O autor e participante do processo de formulação da política afirmou que foi um processo de "longa maturação" que foi se definindo em um processo coletivo de construção vinculado à Reforma Sanitária e "[...] às trajetórias históricas das forças partidárias que se articularam na coligação que, em 2002, levaria à eleição de Lula”. (NARVAI, 2011, p. 24) Apontou, ainda, que a maior decisão estratégica do governo Lula foi ter assumido as proposições recusadas em seu conjunto nos governos democráticos anteriores. (NARVAI, 2011) Conforme já mencionado, uma série de propostas para as políticas de saúde bucal foram retratadas ao longo dos Enatespo e muitas delas não foram reconhecidas como respostas aos problemas bucais pelo Estado. Contudo, cumpre questionar quais as diferenças e semelhanças da política Brasil Sorridente das outras políticas nacionais editadas no Brasil? Como se deu o processo de formulação do documento?

No processo de candidatura presidencial, já existiam pleitos para um programa de saúde bucal "mais efetivo" para a população de baixa renda pelo CFO. ${ }^{92}$

Miguel Nobre em entrevista à autora, Porto Alegre, 2014. 
Apesar de não constarem ações voltadas para a saúde bucal no projeto de governo de 2002, a setorial nacional de saúde do PT, a partir de reuniões regionais, vinha discutindo ações para a saúde bucal segundo relato dos entrevistados.

Após a eleição do presidente Luiz Inácio Lula da Silva, reuniram-se em São Paulo (SP), militantes do PT, Partido Comunista do Brasil (PC do B) e Partido Socialista Brasileiro (PSB), no dia 24 de novembro de 2002, a fim de elaborar uma proposta para a saúde bucal direcionado à equipe de transição do governo Lula. (FOME..., 2002)

Político. Político-partidário. É isso que eu estou me referindo, são pessoas que eram militantes dos partidos aliados que na época faziam parte da coligação do presidente Lula, que era PT, PCdoB, PCB. Hegemonicamente petista, né? Mas tinha gente de outros partidos também, mas o recorte era recorte político. Um recorte que já vinha lá desde o Mbro, que é um recorte fundamentalmente político, de contra hegemônico, de pessoas da Odontologia vinculados a área pública com proposta contra hegemônicas, desse grupo de construtores da saúde bucal coletiva todos tinham vinculação partidária, no mínimo política, então é sempre esse grupo que vinha formulando e que logo depois da eleição se reuniu em São Paulo, fizemos o seminário, desse seminário saíram esses nomes e esses nomes foram encaminhados. (Entrevistado 19, professor universitário, gestor)

Muitos desses dentistas também haviam participado do Movimento Sanitário, MBRO e Enatespo e tinham vinculação partidária ou faziam parte de cargos em governos petistas. Aqueles que não participaram dos espaços citados, não tinham filiação partidária ou não participavam de governos do PT enquanto gestores não compuseram o grupo. Este grupo contava com dentistas do campo científico, burocrático e político.

Vou dizer que foi a academia junto com o pessoal de São Paulo, mas um monte de gente assim, de pessoas que estavam já em estados que tinham politicas pública de saúde bucal [...] gente estava construindo assim num grupo maior essa questão de discutir como vai ser uma política nacional, como seria uma política nacional. (Entrevistada 20, professora universitária)

A reunião, que foi convocada pela setorial de saúde do $\mathrm{PT}$, contou com a presença de, aproximadamente, 100 pessoas (GARCIA, 2006) e foram discutidas as linhas gerais de natureza política da Política Brasil Sorridente. (NARVAI, 2011) Foi construído um diagnóstico da situação da saúde bucal bem como identificadas as ações a serem desenvolvidas nos 100 primeiros dias de governo, desenhou-se, 
preliminarmente, o trabalho para a saúde bucal no governo federal, ademais, analisou-se aspectos do perfil do ministro da saúde e do futuro coordenador de saúde bucal do governo Lula. (FOME..., 2002)

O documento é iniciado com uma referência ao Programa Fome Zero do projeto de governo do recém-eleito presidente da república e a relação da saúde bucal com prioridade para as políticas públicas. (FOME..., 2002)

Preliminarmente, consideramos necessário assinalar que o anúncio do Programa Fome Zero como a primeira manifestação do Presidente Eleito ao povo brasileiro sinaliza, clara e inequivocamente, um conjunto de prioridades para as politicas públicas que, em nosso entendimento, inclui a saúde e, nela, a saúde bucal, uma vez que tornar fome zero uma realidade para todos os brasileiros implica assegurar-lhes condições para mastigar bem. E ter dentes é condição para mastigar bem. Manter dentes saudáveis e, na sua falta, prover dentes aos que deles necessitam constitui, sem dúvida, enorme desafio no conjunto de desafios do Programa Fome Zero. Daí nossa consigna: Fome zero, boca cheia de dentes! (FOME..., 2002, p. 1)

Ao associar o projeto de governo da nova presidência "Programa Fome Zero" à condição de ter dentes para mastigar bem, Bartole (2006) afirma que foi aberta uma janela de oportunidades por esta equipe de militantes após o cálculo estratégico para sustentação política da proposta. Garcia (2006) reforça o argumento explicando que o termo janela de oportunidade foi utilizado para expressar a busca pela garantia de entrada e priorização na agenda, hipótese refutada por Narvai (2011) quando afirma que o processo de construção da política é fruto de uma longa construção histórica iniciada no movimento de democratização do país.

Pires (2004) afirma que o nome da proposta política induz a uma falácia de viabilidade de que se as pessoas tiverem dentes sadios, se terá um país sorridente. O autor argumenta que o equívoco pedagógico induz a que o nome da política tome a estrutura física, o dente, como objeto da saúde bucal e não o homem em sua integralidade.

No documento, foram reconhecidas as dificuldades no cenário socioeconômico e político e sustentada a desaprovação de que o ministro da saúde fosse algum ex-ministro do governo Collor. Havia críticas quanto à perda de capacidade de interlocução, interna e externa ao Ministério, da coordenação de saúde bucal, à incapacidade de realização do inquérito epidemiológico SB Brasil - 2000 e apontava-se que a última Conferência Nacional de Saúde Bucal havia ocorrido em 1993.

Foram definidos 23 objetivos de balizamento das ações de saúde bucal no governo Lula enquanto esboço inicial da PNSB, dentre os quais destacam-se: 
- estabelecer com clareza que a saúde bucal no âmbito federal requer uma política e um responsável pelo acompanhamento, controle e avaliação desta política, sendo isso muito mais abrangente do que "aprisionar" a saúde bucal em um órgão da estrutura administrativo-burocrática do MS. Tal política e seu respectivo responsável devem, para cumprir suas funções, estar integrados e articular ações em todos os níveis e instâncias da gestão da saúde, em nível federal, articulando tais ações com as deliberações do Conselho Nacional de Saúde, da Plenária Nacional de Saúde e da Plenária Nacional de Conselheiros;

- construir uma Política Nacional de Saúde Bucal para o governo Lula, com ampla participação da população, dos estados, dos municípios, dos trabalhadores e suas entidades representativas e das entidades odontológicas;

- articular a Política Nacional de Saúde Bucal às políticas de saúde e às demais políticas públicas, de acordo com os princípios e diretrizes do SUS;

- convocar, imediatamente, a III CNSB, a ser realizada em 2003, precedida de conferências municipais e estaduais;

- apoiar a organização do Enatespo e dos Encontros Estaduais de Serviços Públicos Odontológicos, como elemento estratégico da ação do MS, e aprofundar vínculos e relações com estados e municípios, nos termos das relações mantidas pelo nível federal com essas esferas de governo. (FOME..., 2002)

[...] primeiro se formulou o seguinte, se discutia a criação, aí sim, de uma política nacional de saúde bucal que fosse coerente com os princípios do SUS, que surgiu depois naquele documento Fome Zero e Boca Cheia de Dentes. Aquele documento sintetiza justamente o que a gente trabalhou daquela reunião de São Paulo pra se assumir o governo[...] foi discutido pela primeira vez uma coisa mais focada na saúde bucal. (Entrevistado 19, professor universitário, gestor)

Cumpre destacar as políticas preexistentes com a formalização através de documentos e portarias, conforme já ressaltado no presente estudo. Os dois objetivos prioritários para os primeiros 100 dias de governo foram: (i) convocar, definir uma agenda e divulgar, amplamente, a III CNSB; e (ii) apoiar política e administrativamente a finalização do Levantamento Epidemiológico SB-2000, de modo a agilizar processos e, tão rápido quanto possível ao novo governo, anunciar os resultados da pesquisa. (FOME..., 2002) 
Observou-se tomadas de posições distintas entre o papel da academia e da política quanto à ação. Assim, os entrevistados defenderam que existiam membros do campo científico, mas que também eram militantes políticos.

Isso aí desse documento é o documento Fome Zero e Boca Cheia de Dentes, isso é uma palavra de ordem [...] que vai dar o tom da política. (Entrevistado 19, professor universitário, gestor)

[O documento] é a operacionalização, a escrita de como se operacionaliza aquela intenção, aquela intenção é manual das Conferências, ele é listado num rol de ações para materializar em política pública e política pública é ação e não é fala, fala é para academia de diletante, inclui o papel também. Então aqui é ação! Um rol para garantir a ampliação de saúde primaria; E assim, não foi nada autoritário, Aí fica todo ENATESPO dizendo que um grupo 'PT-Comitê' não, nada de 'PT-Comitê'. As pessoas que historicamente se legitimaram no processo de luta e da disputa, estão lá. (Entrevistado 22, dentista, professor universitário)

Foram ainda citados os nomes de pessoas com o perfil desejado pelo grupo para assumir a Coordenação de Saúde Bucal: Gilberto Pucca Jr. (PR); Helenita Correa Ely (RS); Marco Antonio Manfredini (SP); Paulo Capel Narvai (SP); Renato César Ferreira (MG); e Rozangela Fernandes Camapum (DF). Uma comissão de representantes também foi escolhida para acompanhar o desenvolvimento desta proposta junto à Equipe de Transição do Governo, composta pelos membros: Cleber Ronald (Região Norte-AC); Gilberto Pucca Jr. (Região Sul-PR); José Carrijo Brom (Região Centro-Oeste-GO); Marco Antonio Manfredini (Região Sudeste-SP); Moacir Tavares Martins Filho (Região Nordeste-CE). (FOME..., 2002)

Quatro dias antes da realização da reunião de São Paulo (SP), foi realizada uma reunião em Belo Horizonte, em 20 de novembro de 2002, que também considerava o cenário sócio-político-econômico do país e trazia pautas a respeito da saúde bucal contemplando: articulação com as outras políticas de saúde, alicerce no conceito ampliado de saúde, discussão sobre a política no âmbito da III CNSB, participação e controle popular, proposição de ações para todas as faixas etárias, reorganização da urgência e emergência, prevenção e combate ao câncer bucal, educação permanente, papel e função social das universidades e centros formadores, finalização e divulgação do SB-Brasil 2000, financiamento, discussão sobre o sistema supletivo e sugeria o perfil de coordenador político e com grande capacidade de articulação com bom trânsito intersetorial. Por fim, parabeniza- 
va a iniciativa dos companheiros quanto à convocação da reunião de São Paulo. (CARTA..., 2002)

Ainda no mesmo mês, em 27 de novembro de 2001, os representantes da FIO, José Carrijo Brom, presidente da entidade, juntamente com Rozângela Camapum e outros membros se reuniram com Swendenberger Barbosa, membro da equipe de transição do presidente eleito, e com Humberto Costa, coordenador de Assuntos Sociais da equipe que se comprometeram a incluir as propostas no relatório de transição. Dentre as pautas, constavam: a elaboração de uma política nacional para modificar a saúde bucal no SUS; fortalecer a coordenação nacional; estreitar a relação com estados/municípios e uma atuação mais política no MS; integrar a coordenação aos Conselho Nacional de Saúde, Plenária Nacional dos Conselheiros, Enatespo e MEC, dentre outros; reafirmar a fluoretação das águas de abastecimento; equiparação da equipe de saúde bucal e saúde da família com carga horária semanal de 40 horas; incentivar estados e municípios a criarem centros de referências de especialidades; garantir a realização do SB-Brasil 2000 e espaços institucionais para inserção de programas de educação em saúde bucal; elaborar sistema de informação; incentivar as áreas técnicas de saúde bucal de estados e municípios a participarem dos Conselhos de Saúde; aprovação do Projeto de Lei para regulamentação das profissões auxiliares; integrar com o MEC e inserir no currículo escolar os conceitos e práticas de SB; criar polos de capacitação nos estados e municípios; assim como realizar a III CNSB.

Algumas destas pautas constam no volume especial publicado pelo MBRO na revista Saúde em Debate, em 1986, assim como em outros boletins do Movimento, como a fluoretação das águas, a regulamentação do pessoal auxiliar assim como a inserção de conteúdos sobre saúde bucal nos currículos das escolas. (BARBOSA, 1986; BOLETIM INFORMATIVO DO MOVIMENTO BRASILEIRO DE RENOVAÇÃO ODONTOLÓGICA, 1985) Constam também defesas dos Enatespo como as citadas, além dos centros de referências em especialidades, o sistema de informação e a integração das áreas técnicas dos estados e municípios com o MS.

Em dezembro do mesmo ano, Humberto Costa, que já havia sido definido como o futuro ministro da Saúde, afirmou que o PSF seria uma prioridade em sua gestão. Acrescentou que daria prioridade às questões de saúde bucal citando que o presidente Lula atribuíra a ele a responsabilidade de "cuidar da saúde bucal do povo”. (NINOMURA, 2002, p. A7)

Após o presidente Lula ter sido empossado, as negociações seguiram, quanto ao cargo da coordenação, tendo exercido um papel importante Petrônio Martelli, professor do Departamento de Medicina Social da UFPE. Segundo um Entrevis- 
tado 23, dois nomes da lista citada representavam alternativas reais ao cargo de Coordenação de Saúde Bucal: Rozângela Camapum e Gilberto Alfredo Pucca Jr. A primeira declinou a indicação por questões pessoais, tendo ficado o segundo como sugestão do grupo que havia se reunido em São Paulo. Petrônio Martelli apoiou a indicação de Gilberto Pucca junto ao primeiro ministro da Saúde do governo Lula, Humberto Costa do PT-PE.

Outra reunião ocorreu com um subgrupo dos cirurgiões-dentistas que participaram da formulação do documento Fome Zero e Boca Cheia de Dentes no $21^{\circ}$ Congresso Internacional de Odontologia de São Paulo (CIO-SP), ocorrido de 27 a 30 de janeiro na capital.

A Área Técnica de Saúde Bucal voltou a se denominar enquanto coordenação, ${ }^{93}$ desta vez, como "Coordenação Nacional de Saúde Bucal” pelos novos arranjos institucionais ao interior do Ministério e, em março de 2003, o dr. Gilberto Pucca se tornou o gestor. Após ter assumido o cargo, Gilberto Pucca, através da Portaria $n^{\circ} 36$, de 14 de janeiro de 2004, constituiu a Comissão de Assessoramento da Coordenação Nacional de Saúde Bucal, um grupo de 13 pessoas de diferentes estados para dar seguimento à formalização da PNSB no ano seguinte. Faziam parte da comissão: Cleber Ronald Inácio dos Santos (Secretaria de Saúde do Estado do Acre); Christian Mendez Alcântara (Universidade Federal do Pará - UFPA); Helenita Corrêa Hely (Secretaria Estadual de Saúde do Rio Grande do Sul); Idiana Luvison (Grupo Hospitalar Conceição).

Também integraram a comissão José Carrijo Brom (Secretaria Municipal de Saúde de Goiânia (GO)); Marco Aurélio Peres (Departamento de Saúde Pública da Universidade Federal de Santa Catarina - UFSC); Marco Manfredini (Secretaria Municipal de Saúde de São Paulo - SP); Marcos Azeredo Furquim Werneck (Faculdade de Odontologia da Universidade Federal de Minas Gerais - UFMG); Mauro Rubem de Menezes Jonas (Secretaria Estadual de Saúde de Goiás); Moacir Tavares Martins Filho (Universidade Federal do Ceará - UFC); Paulo Capel Narvai - FSP/USP); Petrônio Martellli (Departamento de Saúde Coletiva do Centro de Pesquisa Aggeu Magalhães da Fundação Oswaldo Cruz, do Ministério da Saúde); e Rozângela Camapum (Secretaria de Saúde do Distrito Federal).

Os participantes da Comissão da reunião de São Paulo contemplaram representantes de todas as regiões do país. Andrade (2008) aponta que a conformação do grupo se fundamentou no triedro saber/ideologia/prática política. Com isto, a autora quis dizer que estavam contemplados profissionais do serviço, da academia, do movimento sindical e da militância política. Em junho/julho de 2003, o

No governo Collor, a DNSB passou a se denominar Coordenação de Saúde Bucal. 
grupo se reuniu novamente para desenhar a política. Idiana Luvison e Helenita Ely fizeram um esboço inicial do documento, a partir da experiência do estado do Rio Grande do Sul e o enviaram para que os outros membros pudessem contribuir. Outros documentos consultados foram protocolos e políticas de saúde bucal de outros locais, como Curitiba e São Paulo.

A comissão estabeleceu longos debates com periodicidade mensal para a efetivação dos termos das diretrizes políticas do novo governo, tendo chegado à conformação de um esboço para a reunião que se realizou no II Fórum Internacional de Saúde Bucal, organizado pela FIO, realizado em Campo Grande, de 12 a 15 de novembro de 2003, onde se obteve o primeiro documento com as Diretrizes da política Brasil Sorridente. A participação das entidades de classe no processo de formulação da política foi limitada à atuação no campo político, com exceção da Fio, que tinha alguns representantes na comissão de assessoramento para construção da política.

Em seguida, o documento foi analisado pelas coordenações estaduais e apresentado ao Conselho Nacional de Saúde (CNS), na $139^{\circ}$ reunião ordinária, de 4 a 6 de fevereiro de 2004. Na reunião seguinte do CNS, realizada nos dias 10 e 11 de março de 2004, foram apresentadas as propostas para a III CNSB, tendo sido aprovado, por unanimidade, o nome de Paulo Capel Narvai para relator-geral da Conferência. O Plenário referendou a composição da Comissão-Executiva proposta pelo ministro da Saúde, a saber: coordenador-geral: Gilberto Alfredo Pucca Júnior; coordenadora-adjunta: Idiana Luvison; secretário-geral: José Carrijo Brom; e secretário-adjunto: Marco Azevedo F. Werneck. Todos os dentistas mencionados integravam a comissão de assessoramento do coordenador Gilberto Pucca Jr. O coordenador nacional recebeu apoio das entidades de classe, como ABO e CFO, que retratava em seu primeiro boletim de 2004 que "o governo estava muito comprometido com a saúde bucal”. (NOVA... 2004, p. 13)

A Política foi publicada em 17 de março de 2004, em Sobral, no estado do Ceará, com a presença dos presidentes das principais entidades odontológicas que homenagearam o então presidente pelo lançamento da política. (BOLETIM DA FEDERAÇÃO INTERESTADUAL DOS ODONTOLOGISTAS, 2004) O documento trata das diretrizes para a reorganização da atenção em saúde bucal em todos os níveis de atenção, baseada em uma concepção de saúde ampliada e tendo o cuidado como "eixo de reorientação do modelo". (BRASIL, 2004, p. 3) A qualificação da atenção básica, sua articulação com a rede de serviços e seu reconhecimento como estratégia na reorganização do modelo de atenção, a integralidade das ações, a utilização da epidemiologia e informações sobre o território para subsidiar as ações, o moni- 
toramento de indicadores, a vigilância à saúde, a definição de política de educação permanente para os trabalhadores, financiamento e agenda de pesquisa foram os pressupostos estabelecidos para a política nacional. (BRASIL, 2004)

Os princípios norteadores do documento são gestão participativa, ética, acesso, acolhimento, vínculo e responsabilidade profissional, com um processo de trabalho baseado em interdisciplinaridade e multiprofissionalismo, integralidade da atenção, intersetorialidade, ampliação e qualificação da assistência, condições de trabalho e parâmetros discutidos entre as coordenações de saúde bucal nacional e estaduais. (BRASIL, 2004)

As ações propostas se baseavam em: promoção e proteção da saúde na perspectiva de integrar a saúde bucal às demais práticas de saúde; fluoretação das águas; educação em saúde considerando diferenças sociais, peculiaridades culturais, integrando as ações educativas com as demais áreas, com sua realização pela equipe de saúde bucal; higiene bucal supervisionada; aplicação tópica de flúor; e ações de recuperação e de reabilitação. $O$ documento situa, ainda, na ampliação e qualificação da atenção básica, a prevenção e controle do câncer bucal, a implantação e o aumento da resolutividade do pronto-atendimento, a inclusão de procedimentos mais complexos, como pulpotomias, restaurações em cavidades mais complexas, pequenas fraturas dentárias e instalação de próteses elementares, assim como a inclusão da reabilitação protética na atenção básica. Foi proposto o modelo baseado nas linhas de cuidado, em faixas etárias e por condições de vida, como em gestantes, na tentativa de superar o modelo biomédico de atenção às doenças. Por fim, a política trata da ampliação e qualificação da atenção secundária e terciária em saúde bucal e referenda a estratégia de saúde da família. (BRASIL, 2004)

Os entrevistados atribuem ao apoio do presidente Luiz Inácio Lula da Silva, como o maior agente facilitador da formulação e implementação da política, assim como ao histórico de militância política, inserção no campo científico e odontológico do grupo de formuladores. Outro fator de importância foi a habilidade na condução do processo de formulação pelo coordenador nacional.

O Humberto Costa [então Ministro da Saúde] foi chamado pelo Lula, e o Lula disse: - Eu quero que na área de saúde quatro coisas tenham prioridade: que ninguém morra por falta de atendimento de urgência (criou SAMU), que não falte medicação para as pessoas básicas (criou o Farmácia Popular), que os hospitais e serviços públicos sejam melhores do que são, mais acolhedores, precisa uma ampla qualificação, e a saúde bucal, que as pessoas não podem ter mais esse quadro de campeão desdentados. (Entrevistada 11, dentista, professora) 
Narvai e Frazão (2008b) também apontaram aspectos relacionados às suas trajetórias com ponto de partida popular, tendo sofrido com urgências odontológicas, como relevantes para seu apoio e a priorização da política. Os autores apontam a saúde bucal retratada em discursos do presidente. O exposto pode ser exemplificado em notícia do jornal Estado de São Paulo, de 9 de outubro de 2004, quando da inauguração do Centro de Especialidades Odontológicas, em Londrina.

No período desta política, observou-se articulação de agentes de distintos campos sociais na formulação da política Brasil Sorridente, no nível nacional. Destaca-se, também, a submissão do PL n 1.537/2003, na Câmara dos Deputados, que dispunha sobre a regulamentação das Profissões de Técnico e Auxiliar em Saúde Bucal, pelo deputado Feu Rosa, do PSDB do Espírito Santo (Quadro 19).

Quanto ao financiamento no período 2003-2010, observou-se aumento do planejamento de recursos, no primeiro governo, e manutenção, no segundo mandato (Tabela 5). Ressalta-se que o orçamento da União e do Ministério da Saúde se elevaram bastante, mas a proporção do aumento não se refletiu na saúde bucal, ainda que tenha ocorrido aumento nos valores planejados para a saúde bucal. Outro ponto de destaque é a inclusão da rubrica relativa à atenção especializada no orçamento, inexistente nos períodos anteriores (Tabela 5). 


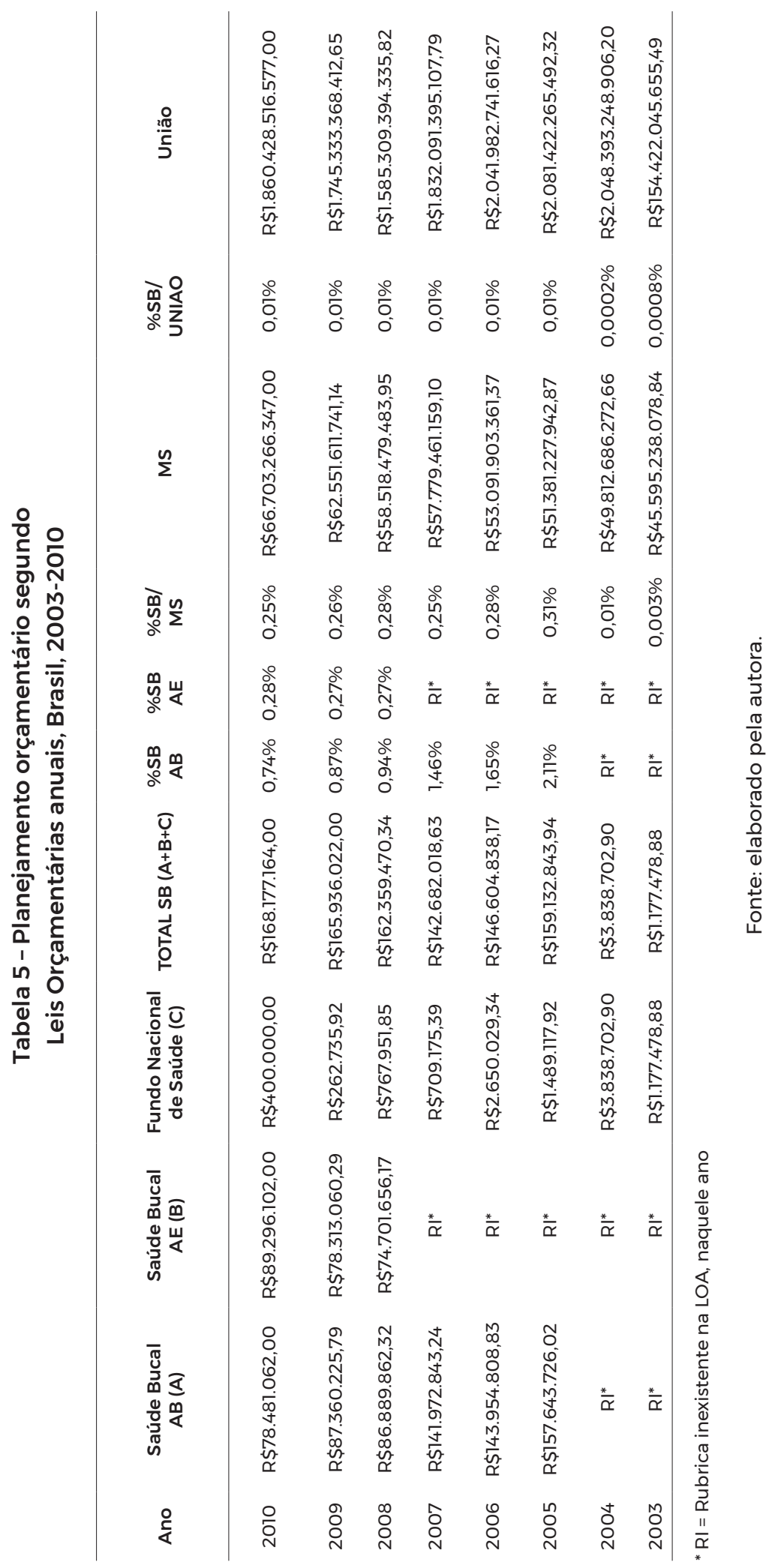

Produção Social da Políticas de Saúde Bucal no Brasil / 189 


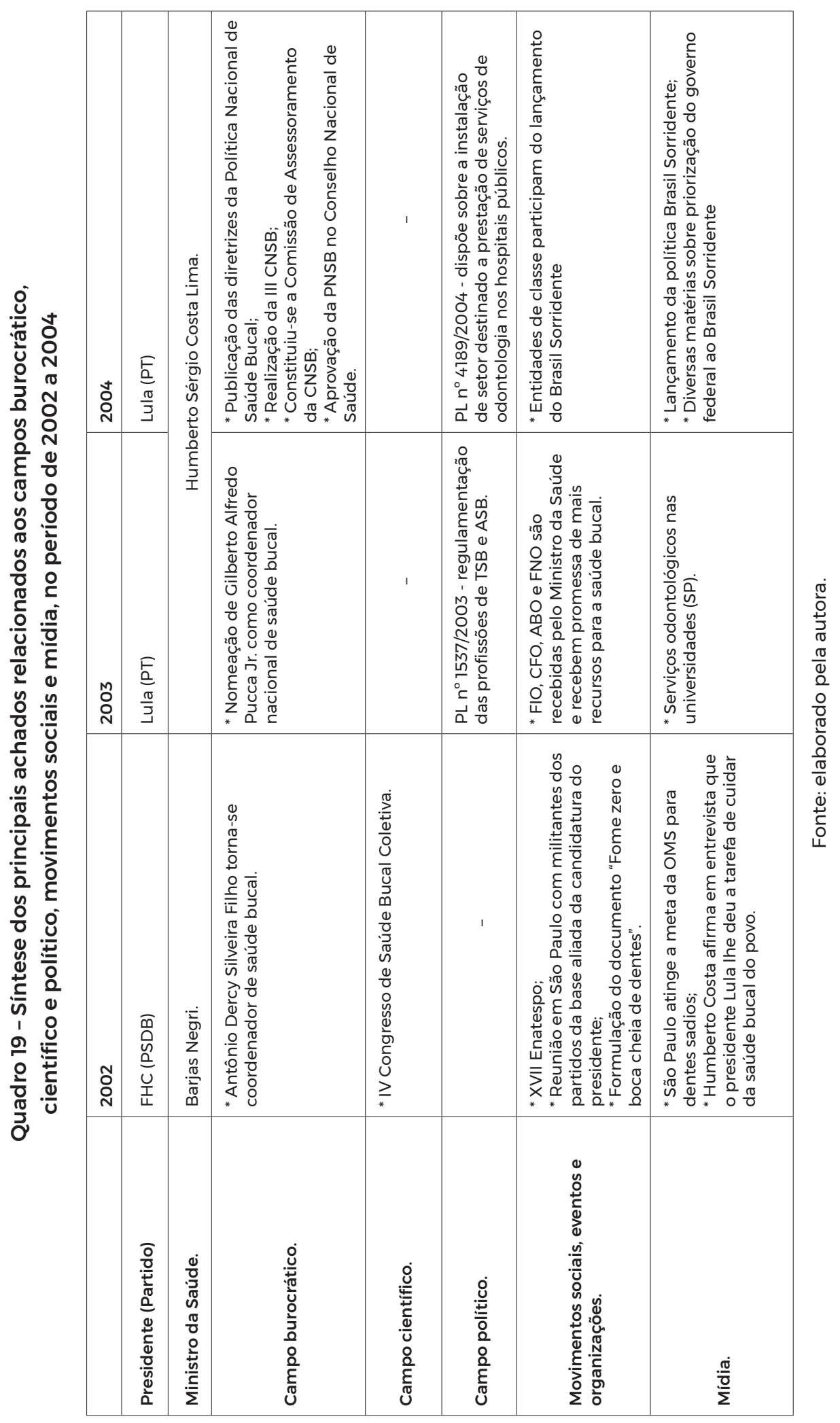




\section{Análise dos participantes e críticos do espaço de formulação das políticas de saúde bucal}

A Política Nacional de Saúde Bucal (Brasil Sorridente) foi formalizada por meio da publicação das diretrizes, em 2004. Oriunda de articulação inicial no interior do campo político, contou com a participação de membros de partidos políticos (PT, PC do B e PSB) que eram dentistas, muitos que haviam participado do MBRO, dos Enatespo, subespaços onde se desenvolveu um pensamento crítico acerca das políticas de saúde bucal, desde a década de 1980. Um dos dentistas, que era do PT, participava da equipe de transição do governo. Swendenberger Barbosa do Nascimento representou uma aliança e apoio da política de saúde bucal também no campo político assim como a aceitação e a sustentação da política pelo ex-presidente Luiz Inácio Lula da Silva foi fundamental para a priorização conferida à política Brasil Sorridente em seu governo (Quadro 20).

No grupo de entrevistados, quatro participantes eram mulheres e sete eram homens. Apesar da maioria da amostra de entrevistados ser representada pelos homens, isto não tem correspondência necessária com o universo, dado ser uma amostra qualitativa. Há indícios de que foi crescente a participação das mulheres no espaço de formulação das políticas de saúde bucal assim como o número de cirurgiãs-dentistas inscritas no Conselho Federal de Odontologia também aumentou.

Dentre os entrevistados, nove participaram da formulação da política e um deles fazia parte do espaço de crítica e também participava dos Enatespo e da Abrasbuco, mas não participou da escrita do documento. A Abrasbuco também não é considerada partícipe do processo de formulação desta política. O presidente do CFO não participou da formulação da política, mas aliou-se ao grupo, manifestando apoio e aglutinando aliados no campo legislativo e junto às outras entidades odontológicas. 


\begin{tabular}{|c|c|c|c|c|c|c|c|c|c|c|c|}
\hline 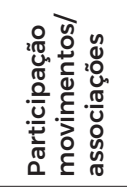 & 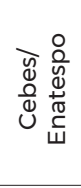 & & 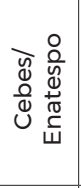 & $\begin{array}{l}0 \\
\text { U⿱士口U } \\
\text {. }\end{array}$ & 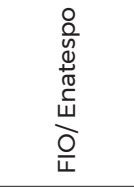 & 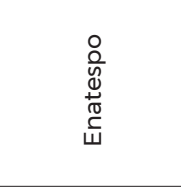 & 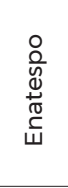 & 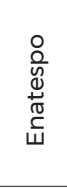 & $\begin{array}{l}0 \\
\frac{0}{0} \\
\stackrel{0}{4} \\
\stackrel{0}{0} \\
w\end{array}$ & $\begin{array}{l}\circ \\
\frac{0}{0} \\
\stackrel{0}{4} \\
\frac{0}{5} \\
w\end{array}$ & $\begin{array}{l}\frac{8}{0} \\
\frac{8}{4} \\
\frac{0}{0} \\
\frac{5}{4}\end{array}$ \\
\hline 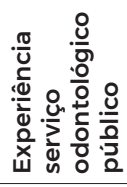 & $\frac{\varepsilon}{\omega}$ & 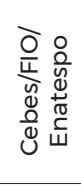 & $\frac{\varepsilon}{n}$ & $\frac{\xi}{i n}$ & $\frac{\varepsilon}{n}$ & $\frac{\varepsilon}{n}$ & $\frac{\varepsilon}{n}$ & $\frac{\varepsilon}{i n}$ & $\frac{\varepsilon}{n}$ & $\frac{\varepsilon}{n}$ & $\frac{\varepsilon}{n}$ \\
\hline 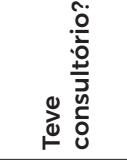 & $\stackrel{20}{Z}$ & $\frac{\varepsilon}{n}$ & $\frac{\varepsilon}{n}$ & $\frac{\varepsilon}{n}$ & $\frac{\varepsilon}{n}$ & $\frac{\varepsilon}{n}$ & $\frac{\varepsilon}{n}$ & $\underline{\xi}$ & $\underset{\frac{0}{2 \pi}}{Z}$ & $\underset{2 \pi}{2}$ & $\frac{\varepsilon}{n}$ \\
\hline 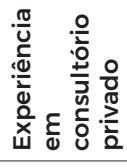 & $\underset{2 \pi}{2 \pi}$ & $\frac{\varepsilon}{n}$ & $\frac{\varepsilon}{n}$ & $\frac{\varepsilon}{i n}$ & $\frac{\varepsilon}{n}$ & $\frac{\varepsilon}{n}$ & $\frac{\varepsilon}{n}$ & $\frac{\xi}{n}$ & $\underset{\frac{20}{2 \pi}}{Z}$ & $\underset{20}{2 \pi}$ & $\frac{\varepsilon}{n}$ \\
\hline 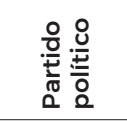 & 5 & $\frac{\varepsilon}{n}$ & 占 & \llcorner & ㄴ & b & $\underset{20}{2 \pi 0}$ & ⺊ & 占 & 占 & $\stackrel{2 \pi}{2 \pi}$ \\
\hline 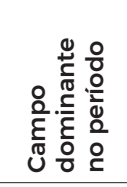 & 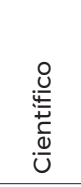 & 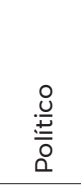 & $\begin{array}{l}0 \\
\frac{0}{0} \\
\frac{0}{0} \\
\frac{1}{0} \\
\frac{0}{0} \\
0\end{array}$ & 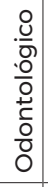 & 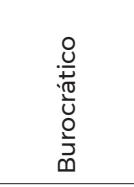 & 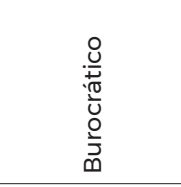 & 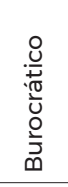 & $\begin{array}{l}0 \\
.0 \\
.0 \\
0 \\
0 \\
0 \\
0 \\
0 \\
0\end{array}$ & 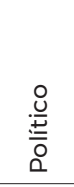 & 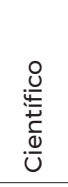 & 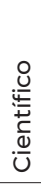 \\
\hline 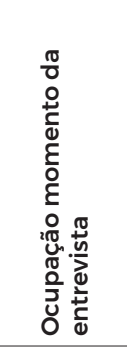 & 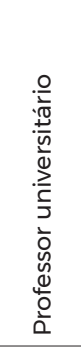 & 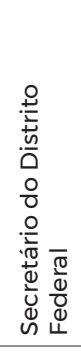 & 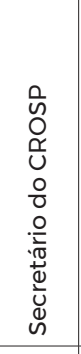 & 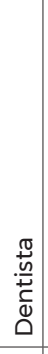 & 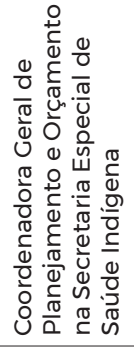 & 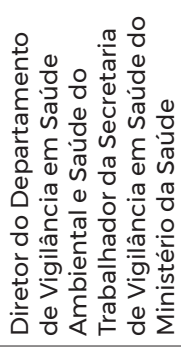 & 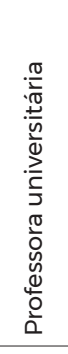 & 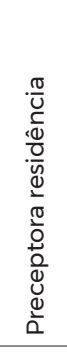 & 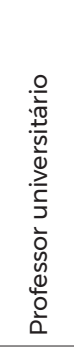 & 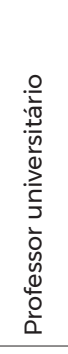 & 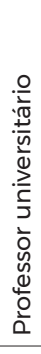 \\
\hline 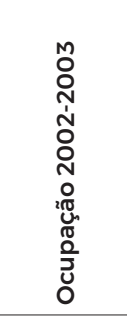 & 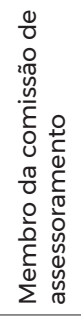 & 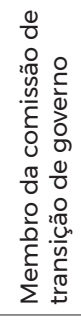 & 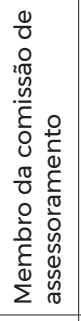 & $\begin{array}{l}0 \\
u \\
u \\
0 \\
0 \\
0 \\
\frac{0}{0} \\
\frac{0}{0} \\
\frac{0}{0} \\
\frac{0}{0}\end{array}$ & 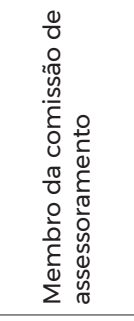 & 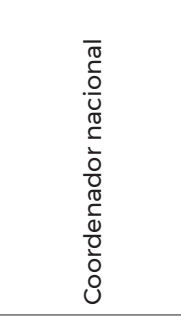 & 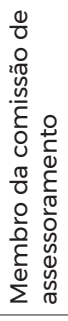 & 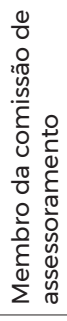 & 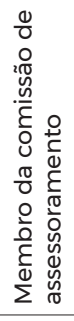 & 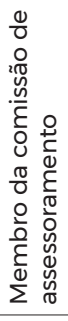 & 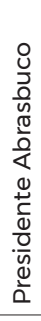 \\
\hline 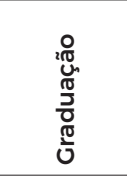 & $\begin{array}{l}\frac{0}{0} \\
\frac{0}{0} \\
\frac{0}{2} \\
\frac{0}{0} \\
0\end{array}$ & $\begin{array}{l}\frac{0}{0} \\
\frac{0}{0} \\
\frac{0}{2} \\
\frac{0}{0} \\
0 \\
0\end{array}$ & $\begin{array}{l}\frac{\pi}{\pi} \\
\frac{0}{0} \\
\frac{1}{0} \\
\frac{0}{0} \\
0\end{array}$ & $\begin{array}{l}\frac{\pi}{2} \\
\frac{0}{0} \\
\frac{0}{0} \\
\frac{0}{0} \\
0\end{array}$ & $\begin{array}{l}\frac{\pi}{0} \\
\frac{0}{0} \\
\frac{2}{0} \\
\frac{0}{0} \\
0\end{array}$ & $\begin{array}{l}\frac{\pi}{7} \\
\frac{0}{0} \\
\frac{0}{0} \\
\frac{0}{0} \\
0\end{array}$ & $\begin{array}{l}\frac{\sigma}{0} \\
\frac{0}{0} \\
\frac{0}{0} \\
\frac{1}{0} \\
0 \\
0\end{array}$ & $\begin{array}{l}\frac{\pi}{0} \\
\frac{0}{0} \\
0 \\
\frac{0}{0} \\
0 \\
0\end{array}$ & $\begin{array}{l}\frac{\pi}{7} \\
\frac{0}{0} \\
\frac{0}{0} \\
0 \\
\frac{0}{0} \\
0\end{array}$ & $\begin{array}{l}\frac{\pi}{7} \\
\frac{0}{0} \\
\frac{0}{0} \\
\frac{0}{0} \\
0 \\
\end{array}$ & $\begin{array}{l}\frac{\pi}{0} \\
\frac{0}{0} \\
\frac{1}{2} \\
\frac{0}{0} \\
0\end{array}$ \\
\hline $\begin{array}{l}\stackrel{0}{0} \\
\text { ] } \\
\underline{0}\end{array}$ & 6 & $\stackrel{\infty}{\circ}$ & 㻤 & ং & กิ & in & $\tilde{\sigma}$ & นก & $\stackrel{\leftrightarrow}{\sigma}$ & $\stackrel{\infty}{\sim}$ & $\stackrel{ \pm}{\perp}$ \\
\hline $\begin{array}{l}\stackrel{8}{x} \\
\stackrel{\omega}{\omega}\end{array}$ & 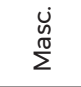 & 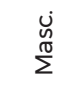 & $\begin{array}{l}\dot{U} \\
\text { In } \\
\text { In }\end{array}$ & $\begin{array}{l}\dot{\varepsilon} \\
\dot{\omega} \\
L\end{array}$ & $\underset{\tilde{\omega}}{\dot{\varepsilon}}$ & 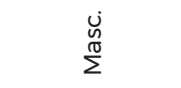 & $\underset{\dot{\Phi}}{\dot{\varepsilon}}$ & $\begin{array}{l}\dot{\varepsilon} \\
\text { ¿ }\end{array}$ & 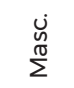 & 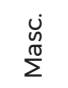 & $\begin{array}{l}\dot{U} \\
\substack{\tilde{J} \\
\Sigma}\end{array}$ \\
\hline $\boldsymbol{\omega}$ & $\stackrel{\circ}{ }$ & $\stackrel{N}{N}$ & 이 & $\bar{m}$ & $\stackrel{M}{M}$ & $\stackrel{\circ}{M}$ & 0 & $=$ & $\infty$ & $\hat{N}$ & กิ \\
\hline
\end{tabular}


No grupo que formulou a política, existe um consenso quanto às tomadas de posição. Foi referido que a PNSB representa a articulação da saúde bucal com as demais políticas de saúde no Sistema Único de Saúde, levando em consideração os determinantes sociais. $O$ consenso pode ser explicado devido à aproximação do grupo quanto à participação em movimentos como o movimento sanitário, MBRO, ECEO, ENATESPO, além de terem debatido estas pautas ao longo dos anos, conforme mencionado.

No primeiro documento editado pelo grupo que participou da reunião em São Paulo, existiam dentistas que exerciam a profissão em consultório privado, em serviços odontológicos públicos, professores universitários e gestores, o que se manifestou na representação dos graus de acumulação de capital nas Figuras 20, 21 e 22. Isto contribuiu para que a política fosse legitimada nos campos burocrático e político, mas, também, no odontológico liberal e científico, com diversas publicações.

A formulação da política foi feita por profissionais com inserção predominante nos campos político, científico e burocrático. Quanto aos cargos no campo burocrático, muitos já possuíam experiência em distintos âmbitos da gestão. O coordenador nacional de Saúde Bucal apresentava alto capital político e burocrático, mas baixo capital científico, à época. Observou-se proximidade nas posições ocupadas assim como nos capitais burocrático e político entre os membros da Comissão de Assessoramento e o coordenador nacional de Saúde Bucal.

$\mathrm{Na}$ Comissão de Assessoramento, o grupo também apresenta proximidade quanto aos capitais científico e burocrático, com exceção do Entrevistado 10, que apresentou maior capital científico que os demais.

Todos os membros da referida comissão apontaram que existiu consenso na formulação da política, tendo sido postas na agenda do Estado as pautas do MBRO, dos Enatespo, das CNSB, dos ECEO, entretanto, ocorreram críticas de agentes que ficaram fora do processo político pertencentes ao campo científico, como Entrevistado 24.

A formulação da política Brasil Sorridente assim como das outras analisadas neste estudo são consistentes com a proposição de Pinell (2010), segundo quem a construção social de um problema bem como a formulação da política correspondente é um processo determinado pelas alianças que vão se conformando entre os grupos sociais que têm interesse no reconhecimento do problema, sem significar que tenham o mesmo ponto de vista sobre o que ele é bem como em relação às medidas a serem tomadas. A aliança implica a negociação da definição do problema. Isso é notável na aliança entre as entidades de classe, a coordenação nacional e os 
grupos de assessoramento na política Brasil Sorridente e na inclusão da equipe de saúde bucal no PSF. Ainda que por motivações distintas, o interesse de reconhecimento do problema fez com que os grupos entrassem em acordo quanto à definição do problema.

\section{Quadro 21 - Entrevistado, concepção do SUS, origem social, sentido da trajetória, local de nascimento}

\begin{tabular}{|c|l|c|c|c|c|c|c|}
\hline E & Concepção SUS & Origem Social & $\begin{array}{c}\text { Sentido da } \\
\text { Trajetória }\end{array}$ & Local Nasc. & $\begin{array}{c}\text { Colégio } \\
\text { Secundário }\end{array}$ & $\begin{array}{c}\text { Região } \\
\text { Estudantil }\end{array}$ & Sim \\
\hline 10 & SUS democrático & Popular & Ascendente & Interior & Público & Sul & Não \\
\hline 23 & SUS democrático & Média & Ascendente & Capital & Público & Nordeste & Sudeste \\
\hline 20 & SUS democrático & Popular & Ascendente & Capital & Privado & Sul & Não \\
\hline 31 & SUS para pobres & Popular & Ascendente & Interior & Privado & Sim \\
\hline 33 & SUS democrático & Média & Estável & Interior & Privado & Centro-Oeste & Sim \\
\hline 6 & SUS democrático & Popular & Ascendente & Interior & Público & Sul & Sim \\
\hline 11 & SUS democrático & Popular & Ascendente & Interior & Privado & Sul & Sim \\
\hline 8 & SUS democrático & Popular & Ascendente & Capital & Privado & Nordeste & Sim \\
\hline 27 & SUS democrático & Popular & Ascendente & Interior & Público & Sudeste & Sim \\
\hline 29 & SUS democrático & Popular & Ascendente & Interior & Público & Sul & Sim \\
\hline
\end{tabular}

Fonte: elaborado pela autora.

A concepção sobre o SUS democrático ligada à redefinição do modelo assistencial dominou o espaço de formulação da PNSB, contudo, a concepção de SUS para pobres esteve presente no discurso do CFO (Quadro 21).

Apesar de referirem se sentir melhor em distintos locais de trabalho como a sala de aula ou o consultório, o serviço público odontológico ou, ainda, o Conselho Nacional de Saúde e o Ministério da Saúde, a maioria se autodeclarava cirurgião-dentista na ficha do hotel. 


\section{Quadro 22 - Entrevistado, segundo distribuição e volume dos capitais científico, político e burocrático}

\begin{tabular}{|c|c|c|c|c|c|c|c|c|c|c|c|c|c|c|c|c|}
\hline E & \multicolumn{3}{|c|}{ Capital Científico } & \multicolumn{5}{c|}{ Capital Político } & \multicolumn{5}{c|}{ Capital Burocrático } & \multicolumn{2}{c|}{$\begin{array}{c}\text { Volume } \\
\text { total }\end{array}$} \\
\hline & & $\uparrow$ & $\uparrow \uparrow$ & $\uparrow \uparrow \uparrow$ & $\uparrow \uparrow \uparrow$ & & $\uparrow$ & $\uparrow \uparrow$ & $\uparrow \uparrow \uparrow$ & $\uparrow \uparrow \uparrow$ & & $\uparrow$ & $\uparrow \uparrow$ & $\uparrow \uparrow \uparrow$ & $\uparrow \uparrow \uparrow \uparrow$ & \\
\hline 10 & & & & & & & & & & & & & & & & 6 \\
\hline 23 & & & & & & & & & & & & & & & & 8 \\
\hline 20 & & & & & & & & & & & & & & & & 4 \\
\hline 31 & & & & & & & & & & & & & & & & 3 \\
\hline 33 & & & & & & & & & & & & & & & & 6 \\
\hline 30 & & & & & & & & & & & & & & & & 7 \\
\hline 6 & & & & & & & & & & & & & & & & 2 \\
\hline 11 & & & & & & & & & & & & & & & & 4 \\
\hline 8 & & & & & & & & & & & & & & & & 5 \\
\hline 27 & & & & & & & & & & & & & & & & 4 \\
\hline 29 & & & & & & & & & & & & & & & & 5 \\
\hline
\end{tabular}

Fonte: elaborado pela autora.

Figura 20 - Agentes segundo capitais burocrático e científico, 2002-2003

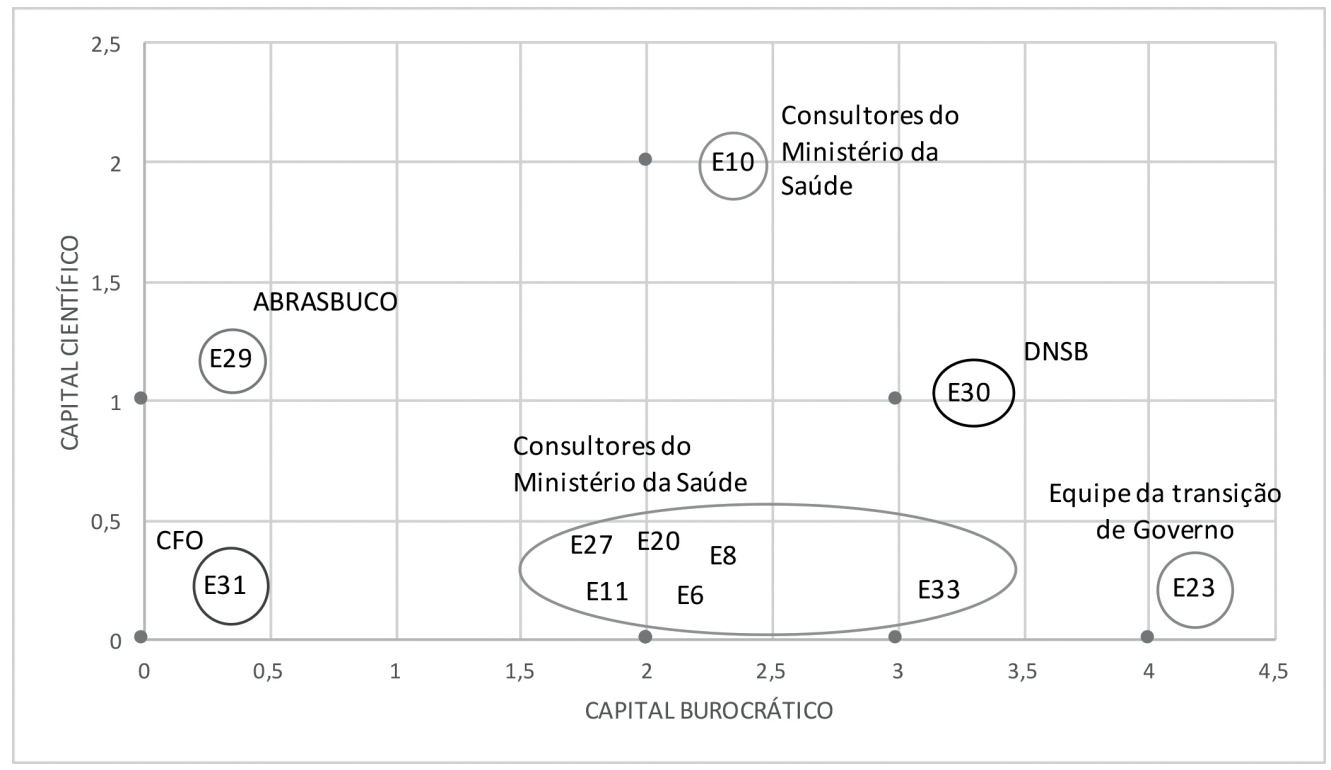

Fonte: elaborado pela autora. 
Figura 21 - Distribuição dos agentes segundo capitais burocrático e político, 2002-2003.

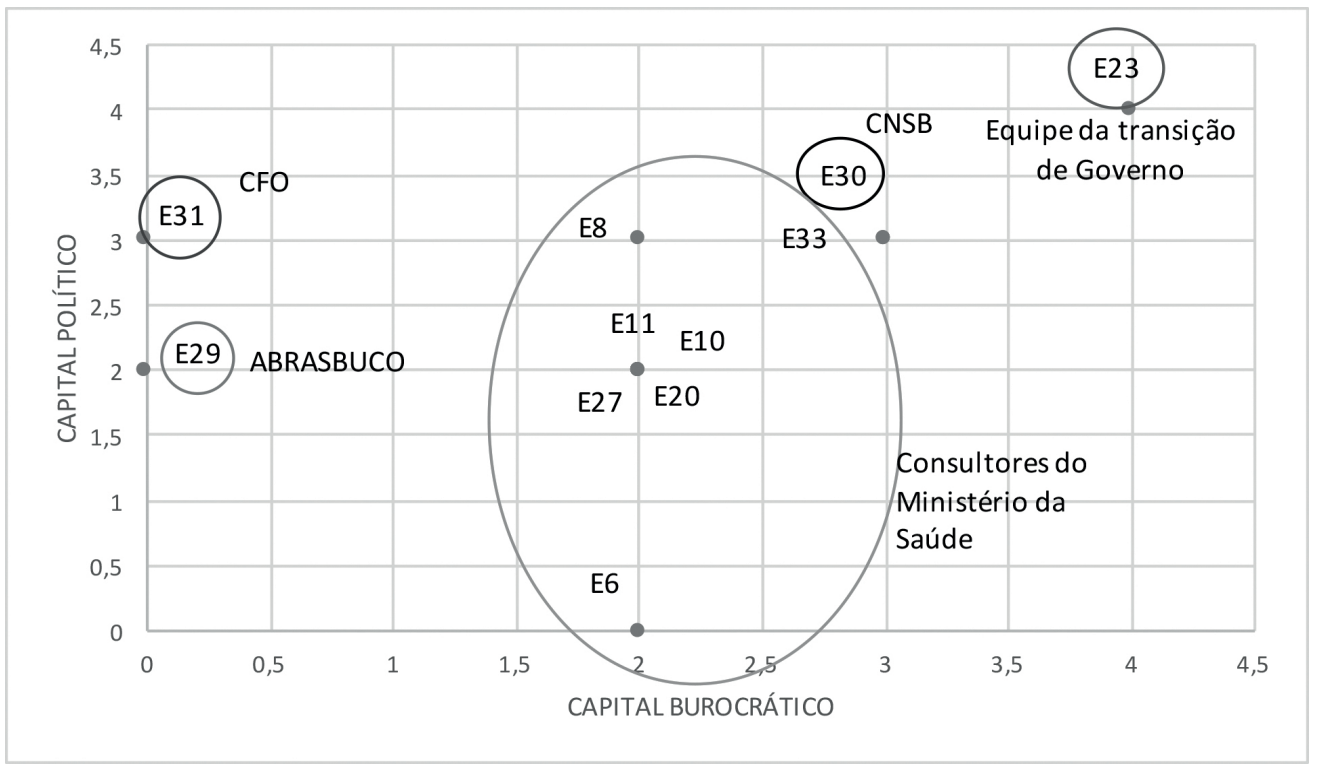

Fonte: elaborado pela autora.

Figura 22 - Distribuição dos agentes segundo capitais científico e político

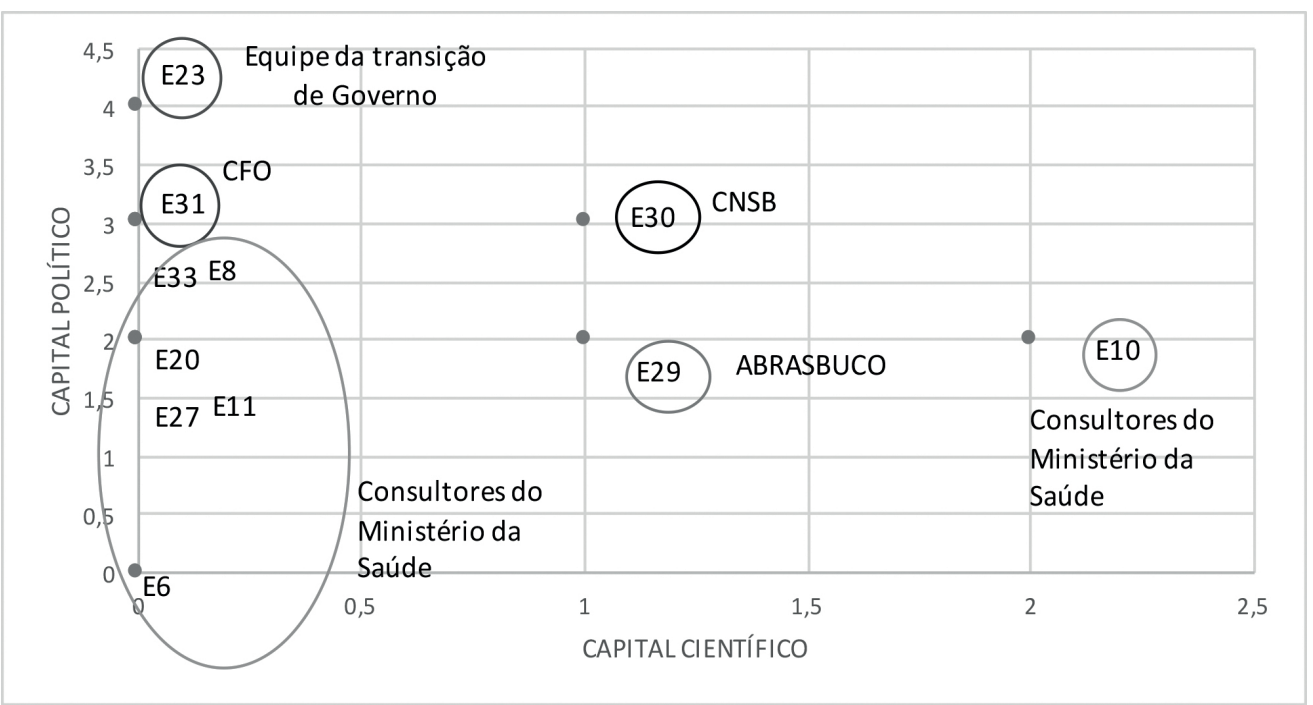

Fonte: elaborado pela autora. 
Dentre aqueles que participaram da Comissão de Assessoramento, a maioria nasceu no interior, é de origem popular, apresentou uma trajetória ascendente, participou de movimento estudantil e foi filiada a partidos políticos de esquerda.

As palavras mais referidas pelos entrevistados apontam para características do cenário sociopolítico e econômico. Novamente, saúde e bucal passam a figurar como palavra muito mencionada assim como nas políticas do período entre 2000 e 2001. Palavras como presidente e governo foram recorrentes. Os participantes da formulação da política apontam que o apoio do presidente foi fundamental na formulação e posteriormente na implementação da política.

Voltamos a história, voltando a história do Lula [...] você teve a indução grande de um presidente operário [...] Ou seja, ele queria saber (isso foi parte da história, eu vi, não foi que me falaram), queria sabe se o CEO ia atender com hora marcada, queria saber quantas pessoas iam ser atendidas, queria saber se o filho do 'não sei que lá' ia ser atendido, isso é demanda das pessoas que precisam de serviço, de usuário, do controle social, é isso! [...] mas não ocorre no governo Dilma. [...] Nenhum óbice contra a presente, muito pelo contrário, porém é uma questão de classe, quer dizer, quem vai procurar por saúde bucal? Isso para mim é uma coisa mensurável na área você tratando de orçamentos, você está tratando de prioridades, como é que faz? (Entrevistado 30, dentista, gestor) 
Figura 23 - Palavras mais frequentes a partir de cinco, seis, sete, nove, dez e onze letras
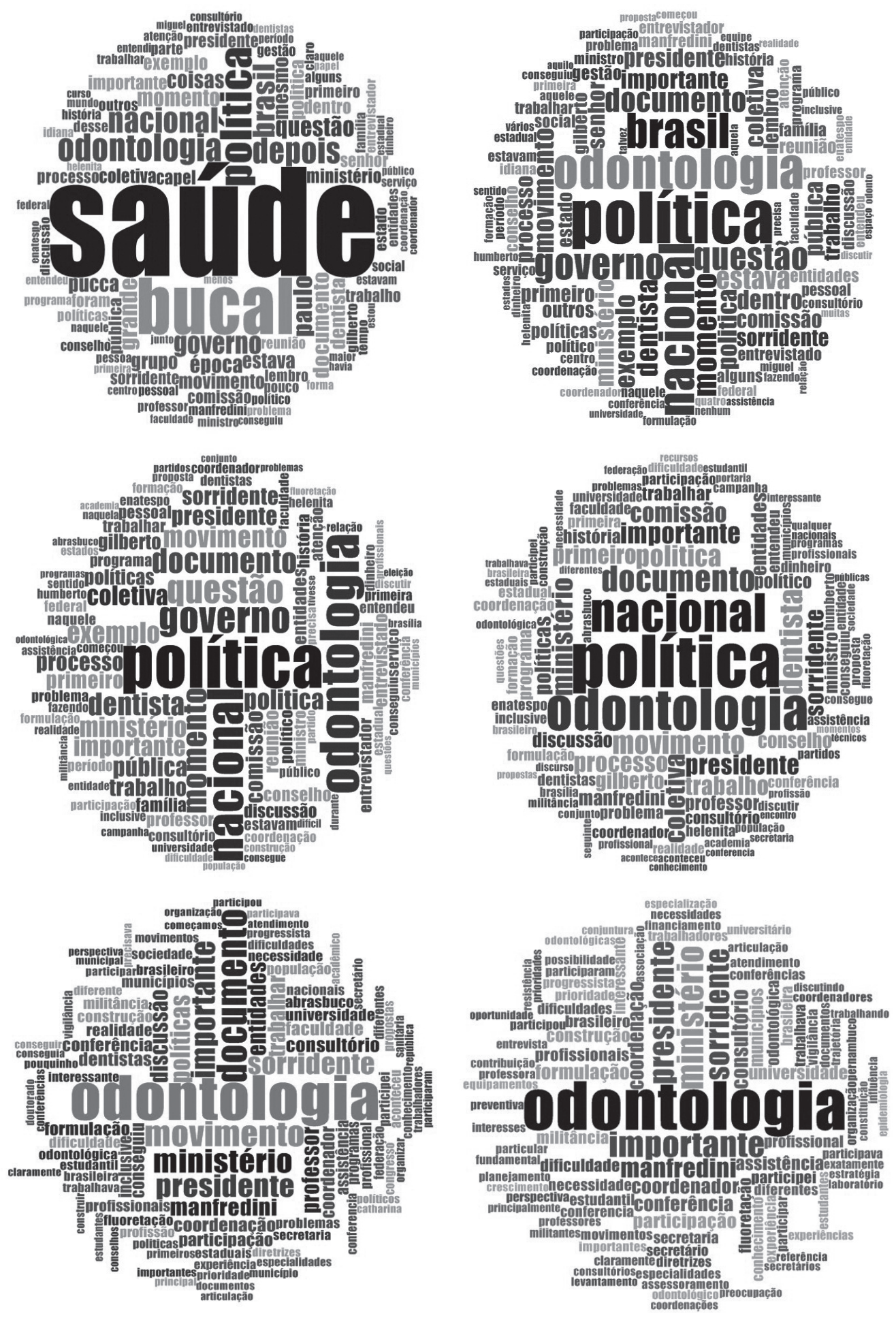

Fonte: elaborado pela autora. 